\title{
Engaging Literacies Through Ecologically Minded Curriculum: Educating \\ Teachers About Indigenous Knowledges Through an Ecojustice Education Framework
}

\author{
Andrejs Kulnieks, Nipissing University
}

Dan Longboat and Kelly Young, Trent University

\begin{abstract}
In this article, we conceptualize curricula through an EcoJustice Education (EJE) framework to educate teachers about Indigenous and environmental education. The primary tasks of EJE are to engage learners in a cultural analysis of the ecological crisis and in the identification of diverse cultural methods that can bring about eco-democratic reforms that emphasize sustainable ways of living. An important method to infuse Indigenous knowledge into curricula is to invite local Elders to share stories that are Indigenous to place. In this paper, however, we consider methods of developing literacies through an engagement with the places within which learners live. We highlight the importance of developing a relationship with food and place, and an understanding about language through an eco-hermeneutic lens (Kulnieks, Longboat, \& Young, 2010; 2011). We demonstrate how an aesthetic teaching form, in this case a poem entitled "Remembering Your Work," can help to foster important connections with local places and the cultural origins of food. Asking students to engage with both oral and literary traditions can promote an important dialogue about intergenerational knowledge, and foster the development of their relationships with food and place.
\end{abstract}

Keywords: EcoJustice Education; Indigenous teachings; intergenerational knowledge; curriculum; literacies 


\section{Engaging Literacies Through Ecologically Minded Curriculum: Educating Teachers About Indigenous Knowledges Through an Ecojustice Education Framework}

Our article emerges from several knowledge sources. We have been working together for over a decade, bringing together an interdisciplinary focus to fostering environmental education. One of us is a trained scholar of Indigenous environmental studies and is originally from Oshwe:en, the Six Nations community on the grand River Territory. Two of us have worked with learners at all levels (K-PhD) and are teacher educators who have spent many years learning from both Anishinaabe and Haudenosaunee Elders in order to inform our teaching and research in environmental education. All of us are involved in research that promotes education that removes barriers to environmental education and that inspires hope that all teachers may explore an integrated approach to environmental learning across the curriculum. The intention of the research and teaching is to bring both Indigenous and Western scientific knowledge systems together into teacher education curriculum. With this desire to integrate comes a hope that there will be more openness to Indigenous knowledge systems in environmental education.

We draw upon an EcoJustice Education (EJE) framework in our conceptualization of curricula in order to provide a balanced and interdisciplinary framework for advancing curriculum that brings together two distinct knowledge systems (IK and Eurocentric), and one that fosters eco-literacy leadership development (Orr, 1992). We define EcoJustice Education as:

An approach that analyzes the increasing destruction of the world's diverse ecosystems, languages and cultures by the globalizing and ethnocentric forces of Western consumer culture. (EcoJustice Dictionary, 2004)

To help students learn about the environment through EJE, we rely on our experiences and the teachings of local Elders in our community.

In this article, we focus on and share our insights about a conceptualization of curricula that brings together Indigenous Knowledges (IKs) and environmental education. Defining IKs is difficult because there are a range of perspectives on Indigenous cultures (Simpson, 2000). It is not our intention to generalize about IKs. Rather, we endeavour to transfer an integrated curriculum to K-12 classrooms. In Original Instructions:Indigenous Teachings for a Sustainable Future, Nelson (2008), conceptualizes IKs as native science preserved in language, revealing what Mohawk (2008) refers to as a repository of knowledge of teachings (p. 173).

\section{Thinking Critically About Curriculum}

A key objective that is prevalent in educational curricula across North America is to develop communication and language skills in order to develop financial literacy (Ministry of Education, 2012). In other words, educators are being asked to foster literacies in mathematics and science, among other areas of curricula, with the understanding that comprehension of these subject areas gives students a better chance to secure employment and a career. The underlying assumption is that some day (relatively soon), an understanding of these subject areas will bring the potential of generating 
wealth, providing security, and becoming part of a consumer culture that values economic knowledge.

Critical pedagogy theorists have delineated the potential and importance of thinking about why we are learning about what we are learning (Darder, Baltodano, \& Torres, 2009). The hidden curriculum drives the not-so-hidden, corporately motivated curriculum within systems of public education. Peter McLaren (2009, as cited in Darder et al.) maintains that the hidden curriculum is hidden by dominant culture and that schooling helps "those who come from the most affluent families" (p. 70) the most. The fact that wealth is largely generated at the price of ecosystems drives the de-emphasis of the development of a relationship with locally situated ecosystems in the curriculum (Kulnieks, Longboat, \& Young, 2010; Basso, 1996; Bringhurst, 2002; Cajete, 1994; Sheridan, 1994). However, there are many educators who are ecologically minded, similar to such thinkers as Veronica Gaylie (2007; 2009) and Williams and Brown (2012) who emphasize the importance of revitalizing knowledge about place through the pedagogy of earth by developing a relationship with the plants that give us sustenance. Educators who maintain gardens can make numerous connections with the curriculum. They realize that developing an understanding of life and the health-giving properties of the local places in which one lives should and can be part of all areas of the curriculum. What also needs to be included in the curriculum is an IK perspective on consumerism, as Nelson (2008) states:

RAFT [Renewing America's Food Traditions] wants to redefine the word consumer to not just mean a blind purchaser in the market-driven, capitalistic economy or an exploiter of resources, but, in the ecological sense, recognizing the fact that all humans have to eat to live and all living beings have to consume food as part of the ecological web of life. (p.190)

David Abrams (1996) and Wendell Berry (1995) have provided volumes of evidence that educators need to be critical about how they ask students to engage with the curriculum, as well as to understand why that engagement is so important. What is clear is that there is an increasing distance developing between human communities and the earth that sustains them. Covering up land where food could be grown with pavement and cement facilitates the destruction of life-giving fresh water and soil required by the everincreasing populations of human civilizations.

\section{Developing Relationships With Food and Place}

An ecojustice framework involves developing an understanding of life-sustaining relationships and the ways in which language frames ways of knowing and being in relation to the natural world (Bowers, 2002; Martusewicz, Edmundson, \& Lupinacci, 2011). An understanding of food and place goes beyond locally grown food as we (as humans) consider the relationships that we need to make with that which sustains us. It is important for educators to provide opportunities to cultivate those relationships as well as to develop an understanding of ancient knowledges of food. Students need opportunities to consider their socio-cultural relationship with food, plants and animals, relationships that have given life to the generations that have lived and flourished previously. 
We offer a poem titled, "Remembering Your Work" (Kulnieks, 2013), that provides an example of how an aesthetic form can be used to teach IKs that foster important connections with local places and the cultural origins of food. Although reading a poem cannot replace the important first-hand experience of traditional teachings from Elders, it can be used to extend understandings gained from Indigenous teachings.

\section{Remembering Your Work}

You are with me when we gather vintage wood for bees to smoke teachings about calm remembered in early summer when we combed honey from fractal forms in the basement heated droplets pour onto thin metal sheets engineered to sustain life toward future generations

I pursue memories of shared time and ancestral stories as worker bees follow their queen into the outer skin of the forest to the maple tree your friend the doctor climbed with the wooden ladder sawed the heavy branch weighed down with pounds of bees mellowed in seeking new realms of continuity years later reminisced as learning faith

as I learned to mow grass near White hives - connected boxes of energy feared stingers in tall grasses around gardens you helped look after hives whisper a continued evocation of stories shared long ago in ominous clouds thunders echo happenings beyond our world connected through gifts of time.

you are with me in the taste of wild strawberries picked near summer solstice with grandmothers showing plants of medicine long before our eyes connect silent peaks along forest path footsteps sing toward charred giant pine trunks

watch ground sift hunted blueberries on topless August afternoons beside lakes and

river sun along new growth tapestries beside ants red and black shuffle into red earth

finger handfuls of blue and black

beside freshly granulated logging roads

on cherished nights walk wet grasses and footpaths

light birch and pine in Precambrian nests

tireless summer months

recall your skills breaking branches between trees

more understood than mechanical teeth

as forest nuts cook on the rocks enveloped by red coals 
decisions become embodied through the shape-shifting moonlight in life-giving surroundings sounds not made by human touch swirl you return as we cook fresh fruit and naturally cured sausages thoughts and stories from long-ago interwoven within mist.

(Kulnieks, 2013)

The above poem reminds us about Indigenous teachings on developing a relationship with seasons and the importance of making close connections with the gifts that the earth provides. It illustrates how intergenerational knowledge can be used to evoke memories and it highlights the ongoing need to find language that fosters engagement with local places. The reflective journey in the poem serves as an example for bringing about cultural methods of EJE in the classroom through focal practices such as interpreting a poem. The EJE framework allows student to explore the non-monetized relationships with food that sustain humans. We have previously written about the importance of revitalizing our relationships with food and place, as well as the cultural origins of food (Kulnieks, Longboat, \& Young, 2010; 2011; 2013). We believe that an essential and substantial part of education should be concerned with helping learners understand the importance of developing a relationship with places that sustain life. Sharing a poem about our relationship with place and food involves a narrative activity and offers an opportunity to share and maintain intergenerational knowledge. Sharing stories about food is an important aspect of environmental education.

Whether the teachings in the poem are about harvesting honey, maple trees and their sap, or gathering berries, we are reminded of intergenerational knowledge that connects food and humans, "with grandmothers showing plants of medicine long before our eyes” (Kulnieks, 2013). This, too, is evident in Mohawk's (2008) understanding that experimentation with plants and animals for food and medicine was and continues to be native science-Indigenous knowledge (p. 172).

Indigenous teachings contained within ancestral stories help to explain that people have been blessed with gifts from the earth, the lives of plant and animals-these teachings are deeply linked to Mohawk's (2008) understanding of a "cultural eco region" (pp. 170-172), which offers food as medicine. Socio-cultural relationships with food include an understanding that power foods provide the energy that sustains civilizations. Many Indigenous peoples, like the Haudenosaunee, considered corn, beans, and squash to be power foods, staples with a variety of nutrients. From an Indigenous perspective, healthy choices involve more than just putting food into the body. To make healthy choices, it is important to consider what ingredients are in the food as well as what macronutrients and micronutrients are provided within the food. Nelson (2008) affirms this when he refers to food as the "primary source of our life and vitality" (p. 182). With Indigenous teachings, we bring notions of "place-based food traditions" (p. 190) into environmental education. As a great place to start, we ask students to engage with what they already know about the plants, the animals, and the places within which they spend time. 
Developing a relationship with food and place, and an understanding of healthy ways of living should include teaching on nutrients and about where to find foods beyond stores and other commercial venues. It is important to understand the natural sources of micronutrients, which are more than just the vitamins that come from the store. Educators can teach about foundational macronutrients and micronutrients and their impacts upon human growth and development. Students can learn about what is available to them through the exponential nutrients that wild edibles offer. Wild animals, birds, fish, and plants provide us with the nutrients that we need to continue our journey on earth. We cannot survive without the food systems that give us life. We need to look past the simple thinking about fats, proteins, carbohydrates, and fibre and look at the provision for deeper physical and spiritual connection that the land freely offers (Goldtooth, 2008, p. 221). Knowledge of food systems and of how to live within them needs to be revitalized. Health depends on the knowledge that intact ecosystems provide. Indigenous people from around the world have maintained a relationship with and knowledge of those food systems through songs, dances, and narratives. Physical, mental, and spiritual beliefs continue to connect us with ancestral knowledges.

Learning how to garden, to grow and gather healthy food, is of the utmost importance. Young children often understand food sources as grocery stores; they have little or no knowledge beyond choosing packages of food and observing payment processes at the counter. Williams and Brown (2012) provide useful methods of curriculum development through "learning gardens":

The learning gardens provide comprehensive, experiential, and transformative experiences to students creating a grounded sense of place before they can truly become stewards of the land. (p. 32)

Going beyond the foods in a garden and learning about the availability of foods outside of the garden is also important to developing a relationship with the ecosystems and bioregions that we inhabit and spend time within. For example, it is important to learn about local ecosystems and about what they produce so that local foods can be reincorporated into one's diet, along with a richer diversity of nutrients. Exposure to the global economic food system is narrowing human access to knowledge of and relationship with locally available foods. The abundant supply of global foods in stores and restaurants removes the necessity of being connected to place, which further limits the ability to develop a relationship with the places that provide foods.

Broadening our understanding of food sources to include wild edibles found in forests and forest productions, marshlands, and wetland productions is important to developing relationships with the animals, fish, and birds that give their lives so that humans can live and be healthy. Reaffirming this relationship between plants, animals, and humans through the sharing of Indigenous stories and poems, such as "Remembering Your Work" (Kulnieks, 2013), are an integral method of teaching about healthy relationships with the earth.

Oral history and cultural practices have kept civilizations alive and vibrant over millennia. There has and continues to be a privileging of print over oral cultural practices that dominate educational systems across North America. This pervasive domination of 
print continues to perpetuate a hyper-separation of humans and the natural world. Language is one factor in our increasingly abstract thinking that enables the ongoing misconception that we are separate from and not reliant on the earth. We propose that in order to foster important understandings regarding food sustainability, an ecojustice framework can be introduced into a curriculum design.

\section{Developing an Ecojustice Pedagogy}

\section{What is the Work of an EcoJustice Educator (EJE)?}

Ecojustice n., the condition or principle of being just or equitable with respect to ecological sustainability and protection of the environment, as well as social and economic issues. (OED, 2008)

The term Ecojustice appears in print as early as 1973 (OED, 2008). Eco, the root of the word ecology derives from the Greek oikos, meaning household, involving the study of relationships (EcoJustice Dictionary, 2004). Connecting ecology, justice, and pedagogy (EJE), involves an analysis of the cultural and linguistic roots and the ecological crisis informed through an interdisciplinary approach to educational theory and practice. The concept of learning has a history of being associated with the notions of linearity and progress. A persistent problem affecting the dissemination of EJE is that the definition and evolution of education have long been associated with this same notion of linearity and progress. Students progress through an education system that is linear in nature with each grade contributing toward a graduating status at the end of high school.

By reviewing the work of EJE, it becomes clear that, as an educational leader, the teacher educator's role is to help foster ecological and cultural literacy, environmental awareness, and activism coupled with a need to develop a familiarity with one's cultural assumptions and ultimately to develop a cultural literacy that moves learners towards sustainable ways of living. EJE is founded upon principles, orientations, and values that recognize the ways in which language and culture are implicated in the enclosure of the commons and ultimately the social and ecological crisis. Both cultural and ecological literacy need to be expanded in classroom practice so that learners have an opportunity to think deeply about the ways in which they can develop meaningful relationships with the earth. Teacher education should be framed in ways that allow candidates to recognize and develop an understanding about their relationship with places that give them life.

Previously, we have outlined the importance of developing a relationship with food and place, and an understanding about language through an eco-hermeneutic lens (Kulnieks, Longboat, \& Young, 2010; 2011). By eco-hermeneutics, we mean tracing the words back to their origin in terms of their relationship with the earth. In order to prepare teacher candidates for the learning garden, we explore the following: root metaphors, the ecological crisis, cultural dysfunction, and the environmental degradation of the commons via a producer-consumer model, and forms of enclosure.

In order to support a curriculum that includes traditional Indigenous teachings and poems, such as, "Remembering Your Work" (Kulnieks, 2013), it is helpful to survey research that informs an ecojustice framework. For example, reviewing Helena NorbergHodge's (1993) film, Ancient Futures: Learning From Ladakh, juxtaposed with seminal 
readings such as: David Orr's (1992) chapter, "Ecological Literacy," in his text, Ecological Literacy: Education and the Transition to a Postmodern World; Gregory Cajete's (1994), Look to the Mountain: An Ecology of Indigenous Education; Daniel Quinn's (1992) novel, Ishmael: An Adventure of the Mind and Spirit; Chet Bowers' (2002) article, Toward an Ecojustice Pedagogy; "Cultural Foundations of the Crisis: A Cultural/Ecological Analysis” in Martusewicz et al.'s (2011), EcoJustice Education: Toward Diverse, Democratic, and Sustainable Communities; and Vandana Shiva's (2005), Earth Democracy: Justice, Sustainability and Peace, provide an important framework for thinking about the importance of various cultural origins of food.

Norberg-Hodge's (1993) film provides a significant commentary on Western notions of progress while also offering a window into the ways in which Indigenous populations of Ladakh have lived for centuries in harmony through non-commodified relationships with natural landscapes. With a preliminary understanding of Western notions of progress as linear and problematic, we move teacher candidates toward a discussion about Orr's (1992) suggestion that "all education is environmental education" (p. 81). We discuss the fact that all humans live in an ecosystem that sustains life. We then turn to the work of Cajete (1994), who outlines non-Western epistemologies and paradigms, as well as contemporary Indigenous approaches to education in order that students develop a sense that a Western model of education is not the only model of pedagogy. It is often the case that students have never been exposed to alternative educational paradigms. These readings offer a basis for a discussion about the need to explore the inter-connectedness of all relationships.

For example, we review Bowers' (2002) article on the historical trajectory of Western ideologies that influence the ways in which education has and continues to be associated with notions of progress and linearity. We spend time considering the hierarchal nature of language in Martusewicz et al.'s (2011) work. We review Vandana Shiva's (2005) seminal work on earth democracy whereby we promote and share experiences of growing practices as she identifies the need to understand the importance of what threatens all community members, that is, water and local commons privatization. Although the idea of a learning garden may seem progressive or even radical in relation to typical forms of curricula, Shiva (2005) understands that gardens promote traditional and intergenerational knowledge that has been shared among Indigenous communities since time immemorial.

To complement the discussion and reinforce understandings, we outline the ecohermeneutic implications of investigating and researching particular terms can change how we understand low and high status knowledge (Kulnieks, Longboat, \& Young, 2010). Eco-hermeneutics involves a review of print-based literature about the ecological crisis (as outlined above), coupled with a land-based approach to place-based learning. We have developed a foundational curriculum that integrates this work of etymological inquiry with the work of ecojustice scholars as a blueprint towards what teacher candidates should consider. To clarify terms and meanings, we review new terms such as root metaphors, the commons, and ecology, for example, root metaphors are described as,

The languaging processes carry forward past ways of thinking that are based on assumptions unique to the culture; these deeply held and generally taken-for- 
granted assumptions, which are derived from the culture's mythopoetic narratives and powerful evocative experiences, are encoded in the words that are called root metaphors. (The Ecojustice Dictionary, 2004)

An effective way to begin an investigation of root metaphors is to consider the issue of various terms with which students are familiar. One example that comes to mind is patriarchy as a way of introducing root metaphors. Students already have a connection with how language changes over time and are able to explore some of the ways in which women paid particular attention to language in order to point out inequities in the workplace. For example, terms such as policemen and firemen exclude women, whereas terms such as policeperson and fireperson are more inclusive. This exploration brings attention to the fact that language is used to exclude and marginalize women, and that language can be used as a vehicle for inclusion. These examples foster a discussion about the ways in which language hides and reveals-ultimately framing what we are able to think about.

The poem, "Remembering Your Work" (Kulnieks, 2013), offers opportunities to explore events from different perspectives related to intergenerational knowledge. For example, "on cherished nights walk wet grasses and footpaths, light birch and pine in Precambrian nests" suggests that language holds stories of life-giving medicines and practices beyond what is written in the poem. Constructing an understanding of how language influences what we are able to think about should include discussions that influence our relationships with the places that we live in/on. A major connection that all cultures and all people have is their connection and reliance on the earth. Connections with the life-giving elements of the earth that we all share can also be defined as the commons. Students should be encouraged to develop an understanding of and a relationship with the cultural and ecological commons in their own communities and to provide examples. We can then move toward a definition of ecology, from the Greek oikos meaning household or relationships and have a deeper discussion about how humans and nature are inter-connected (see Bowers, 2013, p. 20).

Once we have spent time reviewing the theoretical foundations of an ecojustice framework, we can enact activities that help students relate EJE to themselves and identity-formation. For example, we can share examples of non-commodified relationships in our community and in our personal relationships by comparing relations that our ancestors engaged in with the associations with which we currently engage. A considerable amount of time is often needed to help students to recognize the difference between commodified and non-commodified relationships and their links to forms of enclosure that influence our daily lives. For example, we can discuss the implications of the introduction of land ownership and the commodification of waters across the Earth that are part of the commons.

It is important to articulate an EJE framework by naming root metaphors as described in Bowers' (2002) article, and the hierarchies of language as outlined in Martusewicz et al.'s (2011) Chapter 3 and relating these to media campaigns that reinforce that progress is unproblematic and linear. For example, we can explore the ways in which advertising campaigns promote new and improved products such as dishwashing soap and question why notions of progress are taken-for-granted in promoting household 
commodities. This can lead to a discussion about low versus high status knowledgeprint being at the highest level-perpetuated in educational settings. What is often perceived as low status knowledge tends to involve knowledge that does not contribute to the producer-consumer model, such as, traditions, ceremonies, creative arts, and craft knowledge (among others). All of the connections that learners are able to make as they engage with the research and interpret the poem involve the metaphoric mind.

The metaphoric mind relates to the associations people have when they use words to express thoughts and metaphors. These ideas are inextricably linked with interpretations and what they guide learners to conceptualize. An understanding of the role of metaphor is, "pervasive in everyday life, not just in language, but in thought and action. Our ordinary conceptual system, in terms of which we both think and act, is fundamentally metaphorical in nature” (Lakoff \& Johnson, 1980, p. 3). This realization has contributed to a further understanding of the relationship among metaphors, ecology, and identity-formation that continue to inform an EJE framework.

The powerful metaphorical nature of language is inextricably linked to a concern about the enclosure of the commons (Bowers, 2002; Martusewicz et al., 2011). Thinking about land as something to be owned and looked after can be traced to the Biblical concept of dominance as stewardship. Once we are named as something other than and beyond the earth as part of a system of beliefs, arguments regarding how this should be done ensue, leading towards a further distancing from the places that are to be "looked after." Power struggles over how to do so are inevitable. Over time, the original interpretations of our relationship with the places we live in/on are merged with human desires to thrive and expand into places that were once un-endangered by human growth and "progress." These commons that were uninhabited are ever-increasingly claimed and controlled by various groups of people. We turn to the EcoJustice Dictionary (2004) to help further define what we mean by the commons:

The “commons" are defined as representing both the naturals systems (water, air, soil, forests, oceans, etc.) and the cultural patterns and traditions (intergenerational knowledge ranging from growing and preparing food, medicinal practices, arts, crafts, ceremonies, etc.) that are shared without cost by all members of the community. ("C")

An examination of the ways in which the commons have been enclosed is presented through Western and non-Western traditions since the "nature of the commons varies in terms of different cultures and bioregions” (EcoJustice Dictionary, 2004). An exploration of non-monetized relationships is also outlined since the commons is also described as "what has not been transformed into market relationships" (EcoJustice Dictionary, 2004). As the world becomes increasingly populated, it becomes essential to enable learners to foster relationships with natural common places as well as local environments through practices that help them to understand the life-giving gifts that intact ecosystems provide (Nelson, 2008). Understanding the relevance of the enclosure of the commons and its connection with human health should be part of the curricula of all public systems of education. 
With an EJE framework articulated, we can turn our sights to textual analysis in the close reading of root metaphors. Many educators have used The Lorax as a window for considering the ramifications of economy as separate from the environment (see Pleasants, 2006). Engaging readers in an oral readers' theatre of Dr. Seuss's (1974), The Lorax involves both a theoretical and experiential approach to pedagogy through the development of ecological literacy. Enacting the story orally followed by an analysis of the ways in which the plot of the story involves a capitalistic and progressive approach to the commodification of trees works well to connect learners with some of the major current issues, even though it was written close to 40 years ago. It is important for learners to think about what Nelson (2008), among others, described as an assertion of "our rights as human beings to live and thrive with clean water and healthy food" (p. 184). Students then have the opportunity to reconceptualise, discuss, and begin to write about their own stories and practices as well as taking up Orr's (1992) suggestion to spend time outdoors in the natural world.

Ultimately we can draw upon the teachings of Orr (1992), Shiva (2005), Bowers (2002), and Martusewicz et al. (2011) to help students move toward both theoretical and practical understandings about the importance of the commons and to respond to Orr's (1992) call for ecological literacy as he sees "all education as environmental education" (p. 81). Once outdoors and surrounded by cedar trees, we can encourage students to remember their first encounter with nature and to begin to write their environmental autobiographies under the open sky. We can listen to the birds sing and feel the grass beneath our feet as we write about our earliest memories of nature. Sharing stories that are Indigenous to local places is a way of deepening their relationships with the lifegiving properties of the earth though a pedagogy of place from Indigenous cultures who have held these knowledges since time immemorial. These teachings are synonymous with sustainable relationships with the places that we all live. Re-envisioning these stories in relation with other areas of the curriculum provides an opportunity to reconceptualize and share our writing aloud.

Throughout all of the EJE activities, students deeply consider their own relationships with commodified and non-commodified relations, notions of progress and linearity, and the ways in which culturally produced root metaphors contribute to forms of enclosure and the ecological crisis. Ultimately, it is our hope that teacher candidates will bring an EJE framework into their classrooms. Of course there are difficulties associated with bringing forth an opportunity to deepen their understanding of the pedagogy of place in teacher education. Teacher educators should theorize about the importance of becoming literate in both discourses of critical pedagogy (which espouses a social justice education framework) and EJE (which envisions the social and ecological crisis to be inextricably related to one another). Ultimately, it is our hope that by bringing traditional teaching and readings by Indigenous scholars such as Nelson (2008) and Mohawk (2008) into an integrated approach to curriculum, there will be more openness to IK in $\mathrm{K}-12$ contexts.

\section{Conclusion}

With a deep understanding of the ecological crisis and its links to the social crisis, we aim to examine the cultural roots (and specifically root metaphors encoded in the Western 
dominant English language) of the environmental crisis (Bowers, 2002; Martusewicz et al., 2011). Bringing about an EJE framework is an important form of research that can uncover how education is changing the landscape of social foundations. A considerable amount of scholarly writing on the rationale for EJE research has created a demand for an exploration of educational practices and their effects on and value within educational research. This article is a response to such a demand.

The development of ecological habits of mind involves activities that promote a close reading of root metaphors, an awareness of cultural dysfunction that contributes to the local and global environmental crisis, and an exploration of forms of enclosure. It is essential to provide students with an awareness of how to develop skills that can enable the teaching of ecologies of place. To do so requires opportunities for educators to also deepen their understandings and relationship with mother earth, with food and place. This includes involving intergenerational knowledge as well as an exploration of the various cultural origins of food. In addition, it is important to begin an inquiry about medicinal and healthy plant properties living in local environments that are not found in our supermarkets (see Goldtooth, 2008, Mohawk, 2008, Nelson, 2008, and Ross, 2008). All of these scholars document their deep understanding of the importance of native food revitalization and the need to map these traditions. Through the gift of time and place, we can seek to discover spaces to develop our relationships with local environments and intact ecosystems that provide us with all that we need in order to survive and flourish in the places we call home. 


\section{References}

Abram, D. (1996). The spell of the sensuous: Perception in a more-than-human world. New York, NY: Pantheon Books.

Berry, W. (1995). Another turn of the crank. Washington, DC: Counterpoints.

Basso, K. (1996). Wisdom sits in places: Landscape and language among the Western Apache. Alburqurque, NM: University of New Mexico Press.

Bowers, C. (2002). Toward an eco-justice pedagogy. Environmental Education Research, 8 (1), 21-34.

Bowers, C. (2013). The way forward: Educational reforms that focus on the cultural commons and the linguistic roots of the ecological/cultural crises. Eugene, OR: EcoJustice Press.

Bringhurst, R. (2002). The tree of meaning: Thirteen talks. Kentville, NS: Gaspereau Press.

Cajete, G. (1994). Look to the mountain: An ecology of Indigenous education. Skyland, NC: Kivaki Press.

Darder, A., Baltodano, M., \& Torres, R. (2009). The critical pedagogy reader (2 ${ }^{\text {nd }}$ ed.). New York, NY: Routledge.

Ecojustice. (2008). In the Oxford English Dictionary (OED). Encyclopaedia britannica online academic edition. Encyclopaedia Britannica Inc., Retrieved from http://www.britannica.com/EBchecked/topic/436518/The-Oxford-EnglishDictionary

The Ecojustice Dictionary. (2004, January). Retrieved from http://www.ecojusticeeducation.org

Gaylie, V. (2007). Teaching teachers in a learning garden: Two metaphors. The EcoJustice Review:Educating for the Commons, 1(1), 1-4.

Gaylie, V. (2009). The learning garden: Ecology, teaching and transformation. New York, NY: Peter Lang.

Goldtooth, T. (2008). Protecting the web of life: Indigenous knowledge and biojustice. In M. Nelson (Ed.), Original instructions: Indigenous teachings for a sustainable future (pp.220-228).Rochester, VT: Bear \& Company.

Kulnieks, A. (2013). Remembering your work. Unpublished manuscript. Toronto, ON.

Kulnieks, A., Longboat, D., \& Young, K. (2010). Re-indigenizing learning: An ecohermeneutic approach to learning. AlterNative: An International Journal of Indigenous Peoples, 6(1), 15-24.

Kulnieks, A., Longboat, D., \& Young, K. (2011). Indigenizing curriculum: The 
transformation of environmental education. In D. Stanley \& K. Young, (Eds.), Contemporary studies in Canadian curriculum: Principles, portraits and practices (pp. 351-374). Calgary, Alberta: Detselig Enterprises Ltd.

Kulnieks, A., Longboat, D., \& Young, K. (2013). Indigenizing environmental education: Conceptualizing curriculum that fosters educational leadership. First Nations Perspectives - The Journal of the Manitoba First Nations Education Resource Centre, 5(1), 65-81.

Lakoff, G., \& Johnson, M. (1980). Metaphors we live by. Chicago: The University of Chicago Press.

Martusewicz, R., Edmundson, J., \& Lupinacci, J. (2011). EcoJustice Education: Toward diverse, democratic, and sustainable communities. New York, NY: Routledge.

Ministry of Education. (2012, September). Financial literacy. EduGAINS Newsite. Retrieved from www.edugains.ca/newsite/financialLiteracy

Mohawk, J. (2008). From the first to the last bite: Learning from the food knowledge of our ancestors. In M. Nelson (Ed.), Original instructions: Indigenous teachings for a sustainable future (pp.170-179). Rochester, VT: Bear \& Company.

Nelson, M. (2008). Re-indigenizing our bodies and minds through Native foods. In M. Nelson (Ed.). Original instructions: Indigenous teachings for a sustainable future (pp.180-195). Rochester, VT: Bear \& Company.

Norberg-Hodge, H. (1993). Ancient futures: Learning from Ladakh. San Francisco,CA: Sierra Club Books.

Orr, D. (1992). Ecological literacy: Education and the transition to a postmodern world. Albany, NY: State University of New York Press.

Pleasants, K. (2006). Does environmental education need a thneed? Displacing the Lorax as environmental text. The Canadian Journal of Environmental Education, 11(1) 79-194.

Quinn, D. (1992). Ishmael. New York, NY: Bantam Books.

Ross, J. (2008). On the importance of our connection to food. In M. Nelson (Ed.). Original instructions: Indigenous teachings for a sustainable future (pp.201-205). Rochester, VT: Bear \& Company.

Seuss Geisel, T. (1974). Dr. Seuss story time. New York: Random House.

Sheridan, J. (1994). Alienation and integration: Environmental education in Turtle Island. Unpublished Doctoral Dissertation. University of Alberta, Edmonton, Alberta.

Shiva, V. (2005). Earth democracy: Justice, sustainability and peace. Cambridge: SouthEnd Press. 
Simpson, L. (2000). Anishinaabe ways of knowing. In J. Oakes, R.Riewe, S. Koolage, L. Simpson, \& N. Schuster (Eds.), Aboriginal health, identity, and resources (pp. 165-185). Winnipeg, MB: Departments of Native Studies and Zoology, and Faculty of Graduate Studies, University of Manitoba.

Williams, D., \& Brown, J. (2012). Learning gardens and sustainability education: Bringing life to schools and schools to life. NY: Routledge. 